\title{
Genetic Diagnosis Using Whole Exome Analysis in Two Cases with Malignant Osteopetrosis of Infancy
}

\author{
Korcan Demir1,2, Özlem Nalbantoğlu1, Kadri Karaer3, Hüseyin Anıl Korkmaz1, Melek Yıldız1, \\ Selma Tunç1, Behzat Özkan1 \\ ${ }^{1}$ Dr. Behçet Uz Children's Hospital, Clinic of Pediatric Endocrinology, Izmir, Turkey \\ 2Dokuz Eylül University Faculty of Medicine, Division of Pediatric Endocrinology, Izmir, Turkey \\ 3Intergen Genetics Center, Ankara, Turkey
}

\begin{abstract}
To the Editor,
Malignant osteopetrosis of infancy (MOI) is a lifethreatening form of osteopetrosis characterized by dense, sclerotic and fragile bones, impairment of bone marrow function, entrapment of cranial nerves, and growth retardation $(1,2)$. The underlying mechanism leading to $\mathrm{MOI}$ is possibly an aberration in either the differentiation or function of osteoclasts. Until now, homozygous or compound heterozygous mutations in seven genes (TNFRSF11A, TNFSF11, TCIRG1, CLCN7, OSTM1, SNX10, and PLEKHM1) have been found in $80 \%$ of children with $\mathrm{MOI}$ (2). Detection of the exact cause and provision of genetic counselling via individual mutation analysis of all these genes would be expensive and time-consuming. Whole exome sequencing is being increasingly used given that its cost and the time needed for analysis are similar to that of single-gene sequencing $(3,4)$. In addition, whole exome sequencing offers the probability to detect novel causative genes in the remaining $20 \%$ of patients with $\mathrm{MOI}$.

Our first patient, a 9-day-old male infant, was referred to our institution with hypocalcemia (calcium, $5.4 \mathrm{mg} / \mathrm{dL}$ ). His hemoglobin level was $8.6 \mathrm{~g} / \mathrm{dL}$ and platelet count was $130 \mathrm{000} / \mathrm{mm} 3$. His parents were not relatives. There was no similar case in the family. His weight $\left(3060 \mathrm{~g}, 25^{\text {th }}-50^{\text {th }}\right.$ percentile), length $\left(46 \mathrm{~cm}, 10^{\text {th }}-25^{\text {th }}\right.$ percentile), and head circumference $\left(36 \mathrm{~cm}, 10^{\text {th }}\right.$ percentile) measurements were normal, and no pathological examination finding was noted. Skeletal survey demonstrated sclerotic bones.

The second patient was a 7-day-old female infant with hepatosplenomegaly and hypocalcemia (calcium, $6.8 \mathrm{mg} / \mathrm{dL}$ ). Her parents were relatives, and one of her elder brothers had died at age four months from complications of osteopetrosis
\end{abstract}

without a genetic diagnosis. Physical examination revealed normal weight $\left(3045 \mathrm{~g}, 2^{\text {th }}-50^{\text {th }}\right.$ percentile), length $\left(47.5 \mathrm{~cm}, 10^{\text {th }}-25^{\text {th }}\right.$ percentile), and head circumference (37 cm, 25th percentile), and hepatosplenomegaly. She had thrombocytopenia $\left(139.000 / \mathrm{mm}^{3}\right)$ but no anemia or leukopenia. Radiographic findings revealed a dense skeleton, and the diagnosis of osteopetrosis was suggested.

In these two patients, we employed whole exome analysis with particular attention to the seven candidate genes. The DNA samples of the patients were extracted from peripheral blood. Exome sequencing data generated in Genotypic (India) using HiSeq 2,500 sequencer were analyzed in the Intergen Genetics Centre. In the first case, 31.382 variants were detected. Among the possible causative genes, a novel heterozygous mutation (c.718G>A, p.Gly240Arg), which was strongly predicted to be a disease-causing mutation with in silico analyses with MutationTaster (mutationtaster.org), SIFT (sift.jcvi.org), PolyPhen-2 (genetics.bwh.harvard.edu/pph2), was detected in CLCN7 gene (Figure 1a). Whole gene MiSeq next-generation sequencing of CLCN7 confirmed the abovementioned mutation and detected another novel frameshift mutation as well (Figure 1b), resulting in a compound heterozygous state (c.398_401delTTGG, p.lle133Argfs*49 and c.718G>A, p.Gly240Arg). In the second case, 32.529 variants were detected. A previously reported homozygous nonsense mutation p.GIn746* (c.2236C>T) in TCIRG1 was detected and confirmed using MiSeq next-generation sequencing (Figure 1c). Genetic counselling was provided, and pre-implantation genetic testing was recommended for both families.

Whole exome analysis is a useful method for diseases in which multiple genes play a role in the etiology. However, it should be kept in mind that Sanger sequencing/next- 
Demir et al.
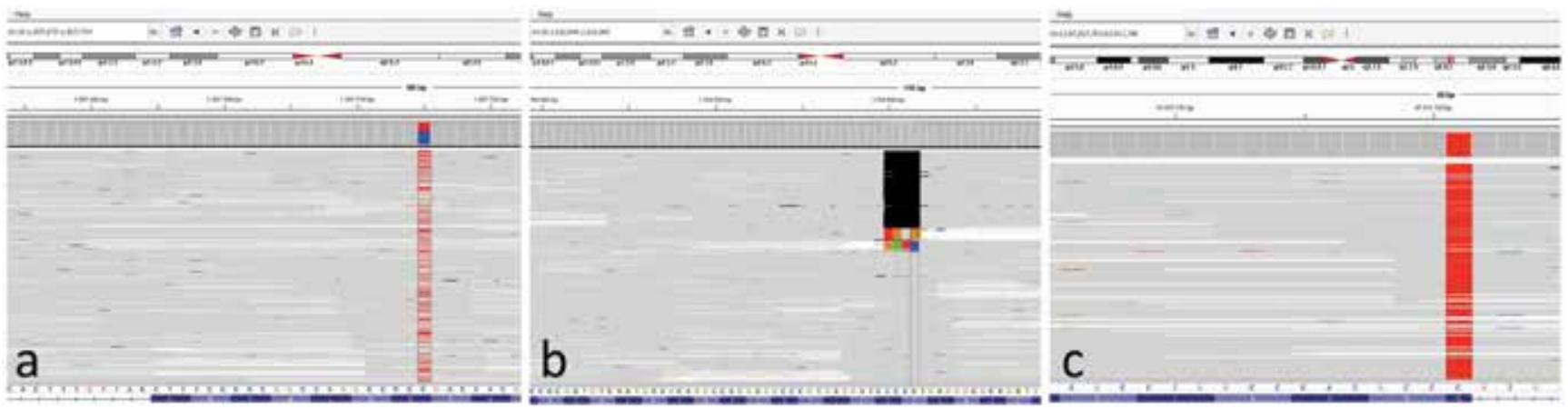

Figure 1. Partial sequences of the relevant regions of the patients (a) heterozygous c.718G $>$ A mutation in exon 8 of CLCN7 gene, (b) heterozygous TTGG deletion (c.398_401delTTGG) in exon 5 of CLCN7 gene, (c) homozygous mutation c.2236C>T mutation in exon 18 of TCIRG1 gene

generation sequencing may be needed when a heterozygous mutation is detected by whole exome sequencing in autosomal recessively inherited candidate genes.

Key words: Mutation, TCIRG1, CLCN7, osteopetrosis, whole exome analysis Conflict of interest: None declared

Received: 10.11 .2015

Accepted: 12.11 .2015

\section{Authorship Contributions}

Concept: Korcan Demir, Behzat Özkan, Design: Korcan Demir, Data Collection or Processing: Korcan Demir, Kadri Karaer, Hüseyin Anıl Korkmaz, Melek Yıldız, Selma Tunç, Analysis or Interpretation: Kadri Karaer, Korcan Demir, Literature Search: Korcan Demir, Özlem Nalbantoğlu, Writing: Korcan Demir, Özlem Nalbantoğlu, Conflict of Interest: No conflict of interest was declared by the authors, Peer-review: Internal peer-reviewed, Financial Disclosure: The authors declared that this study has received no financial support.

\section{References}

1. Del Fattore A, Cappariello A, Teti A. Genetics, pathogenesis and complications of osteopetrosis. Bone 2008;42:19-29.

2. Sobacchi C, Schulz A, Coxon FP, Villa A, Helfrich $M H$. Osteopetrosis: genetics, treatment and new insights into osteoclast function. Nat Rev Endocrinol 2013:9:522-536. Epub 2013 Jul 23

3. Sui W, Ou M, Liang J, Ding M, Chen J, Liu W, Xiao R, Meng $X$, Wang L, Pan X, Zhu P, Xue W, Zhang Y, Lin H, Li F, Zhang J, Dai YI. Rapid gene identification in a Chinese osteopetrosis family by whole exome sequencing. Gene 2013:516:311315. Epub 2013 Jan 4

4. Campeau PM, Lu JT, Sule G, Jiang MM, Bae Y, Madan S, Högler W, Shaw NJ, Mumm S, Gibbs RA, Whyte MP, Lee $\mathrm{BH}$. Whole-exome sequencing identifies mutations in the nucleoside transporter gene SLC29A3 in dysosteosclerosis, a form of osteopetrosis. Hum Mol Genet 2012:21:49044909. Epub 2012 Aug 8 